\title{
A STUDY OF GUNSHOT WOUNDS OF THE BRAIN.
}

\author{
By Captain alan newton, A.A.M.C., and Captain A. E. BRown, a.A.M.C.
}

Probably more fallacious opinions have been expressed about the management of penetrating head injuries than has been the case in any other department of war surgery. It is believed even now, for example, that a preliminary delay in operating, so far from being harmful, may on the contrary be an advantage in these cases. Why head injuries should be supposed to differ from all other war wounds in this respect is difficult to understand. There is also a general impression that the after-results are so deplorable that the time spent in operating upon brain injuries would be better employed in the treatment of more hopeful cases. The technique has been extraordinarily varied, and frequently extremely crude. It has not been generally realized that the greatest gentleness is necessary in any intracranial manipulation.

Many of these fallacies have been exposed by Cushing, ${ }^{2}{ }^{2}$ who has recently published a masterly study of 250 cases of head wounds, and has done so much to improve the results of treatment of these injuries. It would be, therefore, a work of supererogation to attempt to expose them again. Some lessons; nevertheless, have been made clear even in this short series, and attention will be directed to them.

This paper comprises a study of 67 unselected consecutive cases of craniocerebral wounds, and a description of the technique employed. This has been based upon that elaborated by Cushing, and the cases have been grouped in accordance with his classification for the sake of uniformity. As many of the cases were admitted during periods of great pressure of work, the records are, in many instances, very incomplete. There are, in short, "a hundred faults in this thing," and we are forced, in its vindication, to adopt the somewhat truculent excuse of Mercerus" :If I have spent my time ill to write, let not them be so idle as to read."

Literature.-As this paper was written in France, access to the literature of the subject has been difficult. References to the work of various authors will be found throughout the text.

Material.-Of the total 67 cases, 32 were operated upon at a casualty clearing station late in 191\%. A further series of 35 cases were treated at a base hospital in the latter half of 1918. During $191 \%$ the majority of the cases of penetrating head injuries were operated upon at a casualty clearing station; but in 1918, for military reasons, all these cases were transferred direct to the base for operation. It will thus be seen that the same types of injury are included in both series, though, of course, the base hospital cases were more infected, and were, on the whole, less severe, as the more extensive injuries did not survive to reach the base. The time which had elapsed before admission is indicated in each case report.

Technique.-As soon as possible after admission the patient is seen and a brief neurological examination made. A radiogram of the head is then taken. This step should never be omitted; it gives information of the greatest value. The projectile, if present, is localized, and-of even greater importance-the extent and direction of indriving of bone are indicated.

X-ray Technique.-The radiographic work in these cases was done throughout with the usual army outfit--a 12-in. Butt coil, dreadnought interrupter, and MacalasterWiggin tube, working with a spark-gap of $\gamma$ inches and at a distance of about 40 cms. from the plate. The available primary current was 150 volts from accumulators, with an average of 4 ma. through the tube. It will be seen, therefore, that though the outfit was sufficient to produce fair standard results, none of the special advantages required 


\section{GUNSHOT WOUNDS OF THE BRAIN}

for finer points of radiographic diagnosis were available. The exposures were 30 to 40 scconds for a lateral view of the head, and 40 to 45 seconds for the anteroposterior view.

A careful preliminary screen examination was made in all cases in which the presence of a lodging foreign body was probable or possible; but was not accepted as negativing definitely the presence of a small body in the region of the base of the skull or the deeper parts of the face. Therefore, in all these cases, the patient was placed in position for localization of the suspected foreign body, and the first plate of the localizing system (either two-plane or stereoscopic plates) was exposed, and immediately developed, the patient and tube remaining in position meanwhile. In the great majority of cases this practice was quite feasible, but with a very stuporous or restless patient the two plates required by the system must both be taken with as little delay as possible. If a foreign body is detected in the first plate, the second plate is taken and the two are studied.

The counter-claims of stereoscopic plates and of two-plane plates as a means of localization of the foreign body, depend upon the accuracy with which the planes can be determined on the one hand, and upon the practice and skill acquired in interpreting the stereo on the other. In the first plate the whole head is included in the negative, and also in the second if a foreign body is found. But if the first plate shows only local damage to the skull, the second plate is taken with a conical extension diaphragm in position. The diaphragm we use is 6 inches long, and with a diameter increasing from 2 to 3 inches. This necessarily cuts down the field largely, but greatly increases the sharpness of the detail. Small indriven fragments of bone can be shown in this way which would be completely missed with an open diaphragm. A stereoscopic pair of plates with the extension diaphragm in position will reveal the number and relations of the fragments in a way that no other method will. For this purpose, both positions of the tube should be set visually by means of the screen, and the tube shift is $2 \frac{1}{2}$ to $3 \mathrm{cms}$.

Grazing wounds of the scalp, with no lodging foreign body and probably only local damage to the skull, are taken directly with the extension diaphragm in position; and a larger field negative is taken later if required.

Immobilization of the head is secured by placing across it a 3 -inch bandage weighted at the ends by small sandbags, which hang over the sides of the table. The plate is placed between the head and the bandage. The head is raised slightly in both anteroposterior and lateral planes, to ensure correctness of plane, being rested on an ordinary 1-ft.-square $x$-ray plate box. As the need for accurate reproduction of previous $x$-ray positions has not arisen, no mechanical apparatus for this purpose has been employed.

Anæsthesia.-Early in the series a general anesthetic was the routine practice. This was soon abandoned, and in the great majority of cases local anæsthesia has been employed.

The advantages of local anæsthesia in cranial surgery were first described by Martel ${ }^{1}$ in 1913. His methods have recently been explained by M. E. Rochard, and at the ensuing discussion at a meeting of the Société de Chirurgie, Duval and others agreed upon their value. Cushing attributes the improvement in his results in part to the adoption of local anæsthesia. The advantages may be briefly summarized as follows :-

1. The patient can be placed in any suitable position, and this position can be changed during the operation.

2 . There is less hæmorrhage from the sealp, and the elevated position of the head diminishes the venous oozing from the brain. This has been pointed out by Martel, who states that ether narcosis increases cerebral hæmorrhage owing to the increase in arterial tension. Ether also provokes an increase in the secretion of cerebrospinal fluid, and so augments the intraventricular pressure. (Cushing.)

3. Post-operative vomiting is avoided.

4. Cleansing of the track of the missile is facilitated by directing the patient to cough gently at a suitable time.

It is not always possible to employ this method with very restless patients. One such case occurred in this series. The patient, from the time of admission, threw himself about 
on the bed and refused to be comforted. Warmed ether was therefore administered by a Shipway apparatus. This is the general anæsthetic of choice.

Technique of Injection in Local Anæsthesia. One hour prior to the operation a hypodermic injection of 1 c.c. omnopon and scopolamine is given (corresponding to $\frac{1}{3} \mathrm{gr}$. morphia). The scalp is then completely shaved; this must be done carefully in order to avoid the common error of leaving loose hair scattered about on the surface of the scalp, which is then prepared with ether, followed by a 3 per cent solution of picric acid in rectified spirit.

A Gray's syringe is employed for the injection of the local anæsthetic, which is a $\frac{1}{2}$ per cent solution of kerocain to which has been added adrenalin in the proportion of 30 drops to 50 c.c. The injection is made at a convenient distance from the wound in such a manner as to encircle the proposed lines of incision. A small quantity is first injected immediately under the skin, followed by a much larger injection under the pericranium. This latter injection raises a wheal about half an inch in height. It is usually possible to proceed at once to the operation.

Operative Technique.-The operative technique has been constantly modified and improved, and varies considerably according to the requirements of the individual case. It is useless to attempt to do modern head surgery with obsolete instruments. Trephines and old-pattern rongeurs belong now to surgical museums, and have been entirely replaced by Hudson or Doyen burrs, Montenovesi's rongeurs, and parrot-bill biting forceps. These instruments are essential.

The following summary indicates the general steps of the operative treatment: (1) Excision of wound of scalp; (2) Removal of fracture en bloc; (3) Removal of bone fragments and projectile from brain by the catheter method; (4) Irrigation of wound of the brain : (5) Careful suture of the scalp wound in two layers, with or without drainage or B.I.P.P. pack.

1. Excision of THE Wound.- This must be thorough. If an infected area is left it will reinfect the whole suture line. Gray ${ }^{5}$ has shown that after very extensive excisions the wound can be sutured completely by the use of well-planned plastic flaps. Where possible the wounds have been excised by including them in the course of a straight or curved incision. In cases where, owing to the extent of the wound, this has not been possible, Cushing's tripod incision has been employed.

2. Treatment of the Skuld Fracture.-At one time the usual plan was to make a burr opening close to the fracture, and then expose the dural wound by removing the edge of the fracture with a rongeur. Cushing first introduced the method of en bloc removal. This method has the following advantages: $(a)$ The wound in the bone which contains damaged and infected tissue is completely and cleanly excised. (b) When the fracture is near a venous sinus the whole field is exposed at once by an en bloc removal, so that hæmorrhage can be immediately controlled. (c) It is frequently possible to piece together the indriven fragments like a jig-saw puzzle and so be certain that all the fragments have been removed (see Fig. 85).

In fractures near the base of the skull it is not always possible to remove the fracture en bloc, but this is the method of choice. The technique consists in making two or more burr openings as near as possible to the fracture, and then uniting these openings by a rongeur. The whole fracture can then be lifted out in one piece.

3. Treatument of The Wound in the Dura.-- Unless the dural wound is very ragged it is not excised. In four cases the dura was sutured, and in one case, where a large dural defect with little cortical damage was found, this was repaired by a graft from the temporal fascia. Such procedures are only wise in cases which are operated upon soon after the infliction of the wound.

Willems ${ }^{6}$ has recently reported a series of 46 cases of craniocerebral wounds, in 18 of which the dura was sutured. These 18 cases recovered.

4. The Cerebral Wound.-Much time and more patience are required for the successful cleansing of the cerebral wound if this be at all extensive. All the indriven fragments must be removed and, if possible, the projectile should be extracted. The 
practice of searching for bone fragments in the brain with the finger is one to be strongly condemned. Even when performed with great care it must result in increased damage to the brain. All fragments should be localized by a rubber catheter to which is attached a Carrel-Gentil syringe. With such a catheter very minute fragments can be detected. During this exploration the whole wound is irrigated with saline or Dakin's solution, and some of the smaller fragments are removed in this way. The greater number of fragments are more easily removed by a sinus forceps introduced in the direction and to the depth indicated by the catheter. In several cases in this series, one to one and a half hours were spent in the patient removal of fragments. The projectile when present should be removed if possible. A magnet is very useful for this purpose, but unfortunately was not available for use in this series. In one case Ferguson's ${ }^{7}$ apparatus was employed with success in the localization and removal of a metallic fragment in the frontal lobe.

With reference to the advisability of making a prolonged search for the projectile, Monprofit and Courty ${ }^{8}$ state that wounded men with a retained projectile have no higher mortality than those cases in which the projectile has passed through, and that the mortality where the projectile has been immediately extracted does not seem less than in similar cases where the projectile was not extracted.

Marie $^{9}$ has stated that he observed 31 old cases of intracranial projectiles, in $\mathbf{2 9}$ of which there was absolute tolerance, and in only 2 cases were there epileptiform crises.

Cushing believes that retained bone fragments are more likely to produce subsequent complications than are metallic fragments, though these are infected and should always be removed if possible.

The disorganized brain and blood-clots are removed by irrigation, Dakin's solution heing usually employed. The irrigation should be thorough, and-a point of even more importance - not too forceful. Vigorous irrigation spreads infection.

Great care is necessary to achieve absolute hæmostasis. Gentleness in manipulation is essential. Bleeding points should be controlled by ligatures of fine catgut, or by a small piece of muscle, which is a most efficient hæmostatic agent. Cushing's wire clips are very useful, but were not at our disposal. Wounds of a venous sinus were treated by fascial or muscle grafts.

5. Suture of THe Wound.-At first the wounds were closed by through-and-through silkworm-gut sutures passing through all the layers of the scalp. This is a rough method of suture, involving inaccurate apposition, undue compression of tissues, and frequently producing infection around the suture holes. It has been replaced by suture in two layers, in which the epicranial aponeurosis is sutured by catgut and the skin is then united by horse-hair ; these sutures are removed on the fourth day. This method ensures accuracy of apposition without undue tension, and so decreases the incidence of wound infection.

Drainage.-This depends upon the extent of the injury and the degree of infection, i.e., the time which has elapsed since the infliction of the wound. In those cases in which the wound was small and the operation early, no drainage was necessary. In more extensive injuries a glove rubber drain was employed for the first twenty-four to forty-eight hours. In cases in which the operation was not performed for two to five days after the infliction of the wound this method was not satisfactory, as it frequently failed to prevent the spread of infection in the wound. Bacteriological examination in these cases revealed the presence of anaerobic bacilli, streptococci, and numerous other organisms. In this type of case a B.I.P.P. pack proved of great value.

The B.I.P.P. Pack.-This pack consists of a thin strip of gauze soaked in paraffin and then impregnated with bismuth, iodoform, and paraffin paste (Rutherford Morison's formula). The pack is placed lightly in the wound in such a manner that all recesses superficial to the cerebral wound are filled and no dead spaces remain. The wound is then sutured over the pack, one end of which protrudes through the incision. The pack is removed on the third day and replaced by a smaller one. Three days later the latter is removed, and the aperture through which the pack protruded is closed by secondary suture or allowed to heal by granulation. This method has proved of the greatest service in infected cases. The pack acts by obliterating all dead spaces, thus decreasing the risk 
of infection, and, owing to its oily nature, by preventing adhesion of surfaces and consequent pocketing. Drainage is quite free and is usually slight in quantity, and-an important point-reinfection from the skin is prevented. Many of the severely infected cases healed uneventfully without the formation of a cerebral hernia.

'The difficulty of treatment of brain injuries which had been neglected for several days was doubtless responsible for the introduction of the so-called open-flap method of treatment of the penetrating head wounds - a method in which the skin flaps are sutured back, thus widely exposing the cerebral injury. A hernia cerebri forms, and later, in successful cases, the flaps are re-sutured into place. Our experience has been that the brain injury, if satisfactorily cleansed at the operation, will heal uneventfully if reinfection be prevented. The open-flap method simply invites this reinfection, and therefore cannot be t,oo strongly condemned. The following case will illustrate the B.I.P.P. pack method.

Case 1.-Pte. G. N. B. Admitted threc days after the infliction of a wound in the left postparietal region. The wound was dirty and ragged. The patient was stuporous. There were no other abnormal neurological signs. $X$-ray showed a depressed fracture, with indriving of bone fragments to a depth of $1 \frac{1}{2}$ inches.

Operation. - Fracture removed en bloc, numerous small fragments removed from brain. B.I.P.P. pack. Suture in two layers. Bacteriological report on indriven bone fragments says : anacrobic bacilli type $B$. Welchi, long-chain streptococci.

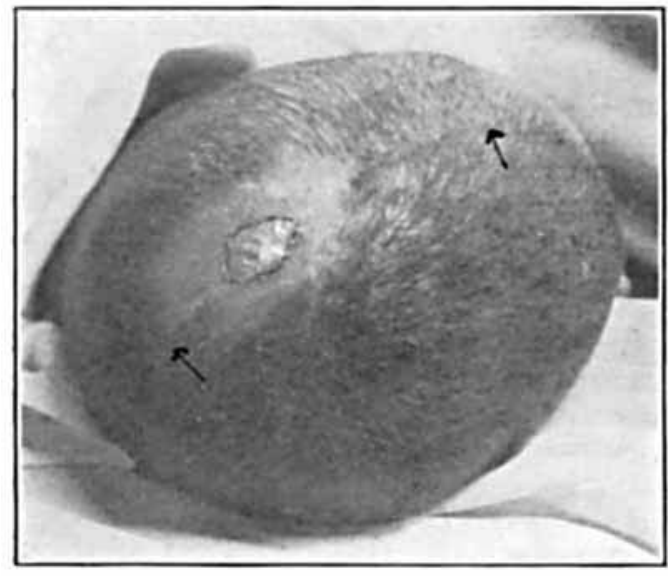
FIG. 71.-Case 1. Granulating area after removal of
B.I.P.P. pack.

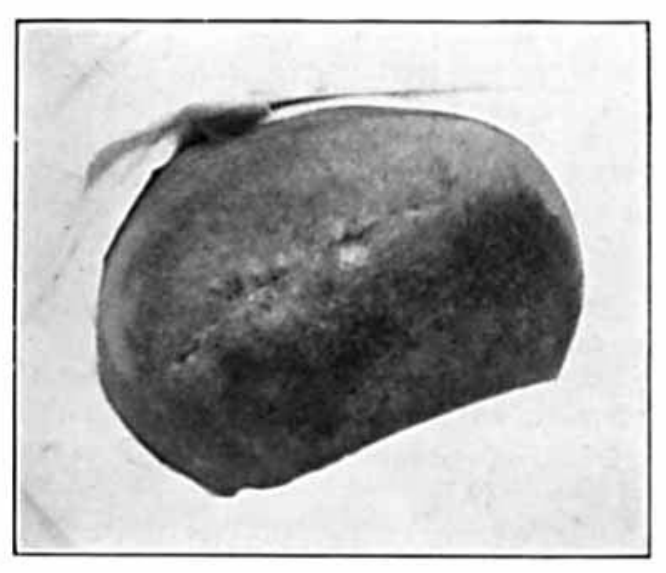

FIG. 72.-Case 1. Seven days after secondary suture.

After-treatment.--Three days after operation the pack was removed and a smaller pack inserted. This pack and the sutures were removed two days later. Wound remained clean, and fourteen days after opcration the small granulating area was closed by secondary suture (Figs. 71, 72). X-ray showed all depressed bone removed.

The patient was quite normal three months after the operation.

After-treatment.-The wound is dressed with B.I.P.P. gauze. This dressing does not adhere to the incision, and at the same time does not easily become displaced. Daily dressing of the wound is necessary, and should be performed by the surgeon himself, in order that due warning may be obtained of the onset of any infective complication.

Treatment of Cerebral Hernia.-The only satisfactory treatment of this condition is prophylactic. A thorough and efficient cleansing of the wound at the operation, i.e., a complete removal of all damaged tissues and foreign bodies, will prevent the formation of a hernia. No satisfactory treatment of a rapidly increasing soft hernia has been devised. Lumbar puncture is sometimes useful, but the majority of these cases terminate fatally. In the more slowly developing hernix treatment is not so difficult. One such case occurred in this series. It subsided in the course of three weeks, during which it was dressed with B.I.P.P. gauze and light pressure applied by a bandage. 
The Treatment of Superficial Infections.-Superficial infections were treated by irrigation with Dakin's fluid. This was introduced with a syringe every four hours. A Carrel tube was found unsatisfactory in head wounds. It was frequently pulled out by the patient, and, further, interfered with the healing of the wound by its pressure.

\section{CLASSIFICATION OF CRANIOCEREBRAL WOUNDS.}

It has been the custom to classify these injuries according to the type of the skull fracture present. This method should be abandoned, for it fails to indicate the extent of the cerebral injury. The fallacy has been exposed by Cushing, whose classification has been adopted in this paper, with the addition of a separate group for wounds of a venous sinus.

Cushing states that there are doubtless imperfections in his scheme, and that other subdivisions may be better, but that it is thrown out merely as a temporary working basis. on which cases may be recorded for purposes of comparison without too much elaboration.

CLASSIFICATION OF CASES AND RESULTS.

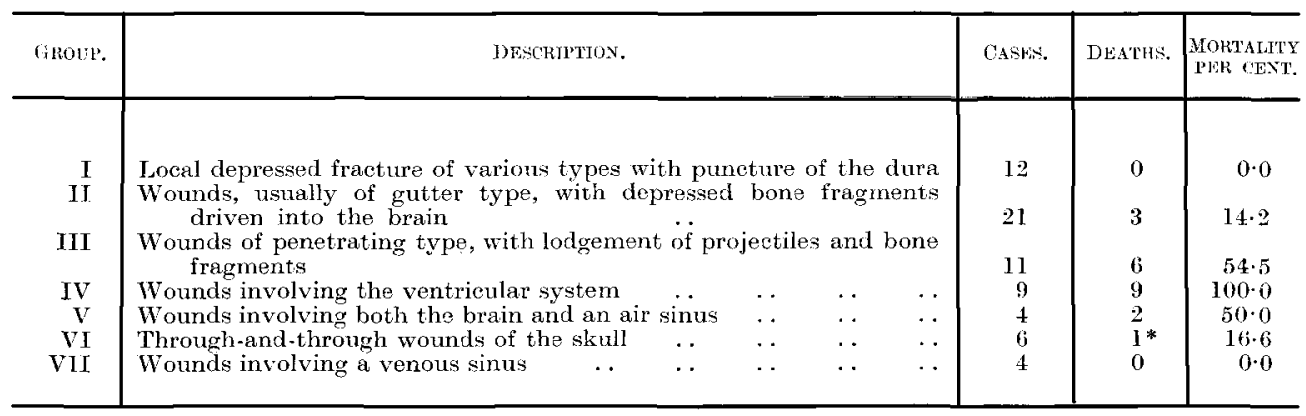

* Two end-results uncertain-probably died.

\section{Group I.-LOCAL DEPRESSED FRACTURES OF VARIOUS TYPES WITH PUNCTURE OF THE DURA.}

In this group are placed those cases in which some fragments of the depressed inner table have been driven through the dura. There is no cerebral hernia, as the skull, though fractured and depressed, still forms a complete covering. The cerebral laceration is slight, but is frequently surrounded by an area of contusion which may give positive signs on neurological examination.

The operative technique is not difficult, as there is no extensive indriving of bone fragments. It is usually possible to suture the wound in the dura in these cases.

Case 2.-Pte. W. S.-Admitted five hours after the infliction of the wound, which was small, and situated in the right post-parietal region. There had been no loss of consciousness, and the patient had been able to walk to the dressing station. There were no abnormal signs on neurological examination.

Operation.--The wound was excised and a small depressed fracture removed. A dural laceration $\frac{1}{2}$ inch in length was exposed, with subjacent superficial cortical laceration. The dura was sutured with fine catgut sutures, and the wound closed without drainage. Healing was uneventful.

This minor type of injury is less frequent than that in which, in addition to the small cortical wound, there is an area of contusion giving rise to disturbances of consciousness, of speech, or of vision, or to interference with sensori-motor functions.

This is illustrated in the following case, in which a hemiplegia was present.

Case 3.-Pte. A. B. Admitted ten hours after injury. Small wound in the right parietal region. Patient was unconscious for two hours, and is still irritable. A left hemiplegia is present. 
The deep reflexes are exaggerated and superficial reflexes absent. Babinski reflex was elicited on the left side.

Operation.-A large depressed fracture of the right parietal bone was removed. There was a small extradural hæmorrhage from a diploic vessel. A dural wound $\frac{3}{4}$ inch in length was sutured, and the wound was then closed without drainage.

The wound had healed and the hemiplegia had completely disappeared fourteen days after the operation.

In another case both sensory and motor centres were involved.

Case 4.-Pte. A. M. Admitted two days after injury, with a glancing wound in the parietal region immediately to the left of the mid-line. $X$-ray examination showed a linear fracture of

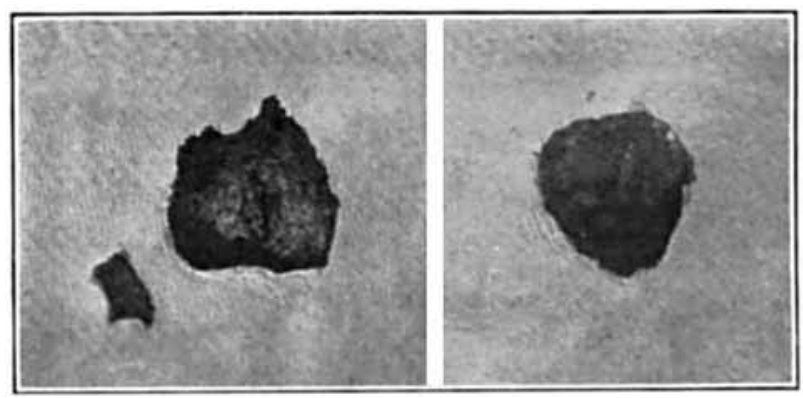

A.

B.

FiG. 73. Case 4. A, Outer table. Separated fragment removed from brain. $B$, Inner table mosaic reconstituted. the outer table. One small depressed fragment of the inner table. Neurological Examination.Motor : normal range but greatly diminished power in all movements of right lower limb. Sensory : defective localization of touch and loss of sense of muscle position in right lower limb. Reflexes : right superficial abdominal and right eremasteric reflexes absent. Right knee-jerk increased. Flexor plantar reflex on left. No reflex elicited on right.

Operation. - Wound excised. Fracture removed en bloc (Fig. 73). The small indriven fragment had penetrated the dura. It was removed, and the wound sutured, with glove-rubber drainage.

Healed well. The abnormal neurological signs had completely subsided at the end of four weeks, when the patient was able to walk normally.

Attention has frequently been directed to the fact that a linear fracture of the outer table may be accompanied by a much more extensive fracture of the inner table. This is illustrated by the following case, in which also a hemiplegia was present.

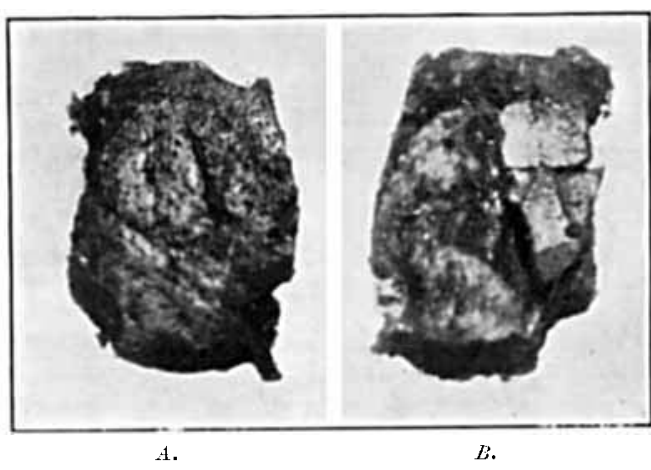

Fia. 74.- Case 5. Ln bloc removal of bone. A. Outer table. $B$. Inner table.

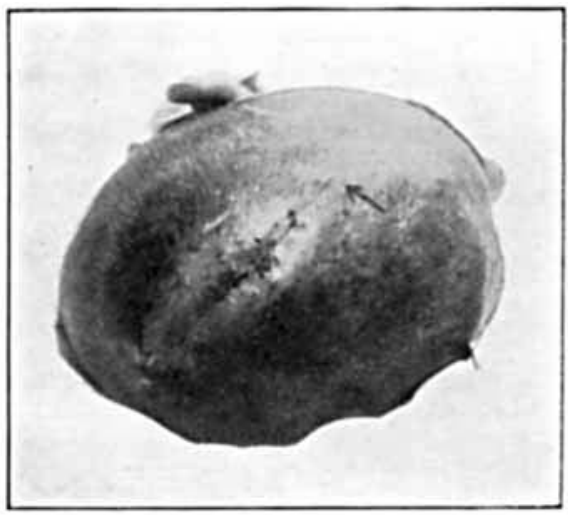

1'IG. 75.-Case 5. Wound seven days after operation.

Case 5.-Pte. J. H. Admitted two days after infliction of wound. This was glancing in type, and was in the left parietal region.

Neurological Signs.-The patient was irritable and strongly resented examination. A right hemiplegia with absent superficial and exaggerated deep refiexes was present. A Babinski reflex was elicited on the right side.

$\boldsymbol{X}$-ray Earamination. - Small depressed fracture

Operation.-Depressed fracture removed en bloc (Fig. 74). The depressed fragments had lacerated the dura. The wound was sutured in two layers, and healed without incident (Fig. 75). 
The hemiplegia rapidly disappeared, and six weeks after the operation the patient was able to walk well.

Occasionally the reverse holds true. Fig. 76 demonstrates an extensive fracture of the outer table, with merely a small depression of the inner table, which had not caused any laceration of the dura. In this case, it must be noted, the skull was exceptionally thick.

Nor is it possible to predict the effect produced by a projectile on the skull. This will be seen by a study of the three following cases, in which metallic fragments have lodged in the bone. In two instances the inner table was fractured in a typical manner, whilst in the third the projectile penetrated the skull without causing much comminution.

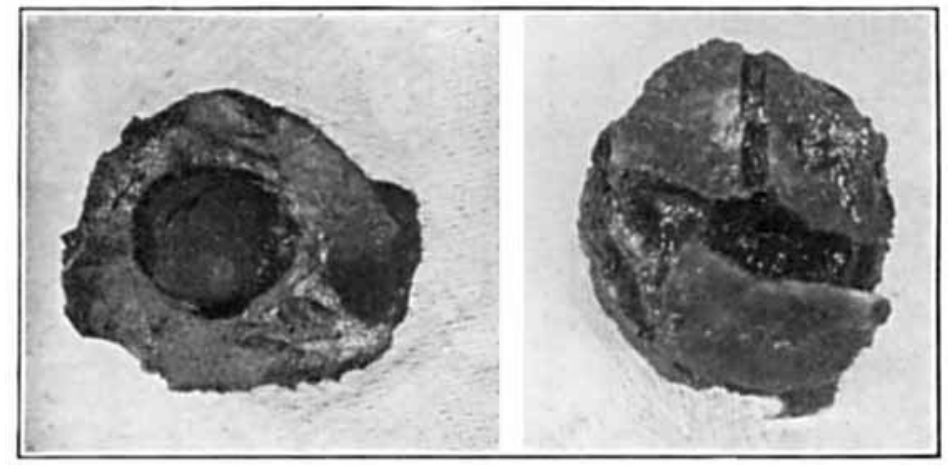

L.

b.

Fig. 77.--Case 6. A. Outer table; slmapnel bullet embedded. B. Mosaio of inner table.

Case 6.-Sgt. G. H. B. Admitted thirty-six hours after the injury with a small punctured wound in the left frontal region. There was no loss of consciousness. The patient was evacuated to the base as a walking case. No abnormal signs were noted on neurological examination.

$X$-ray Report. - Shrapnel bullet embedded in outer table, depressed fracture of inner table.

operation.--Wound cxcised by curved in-

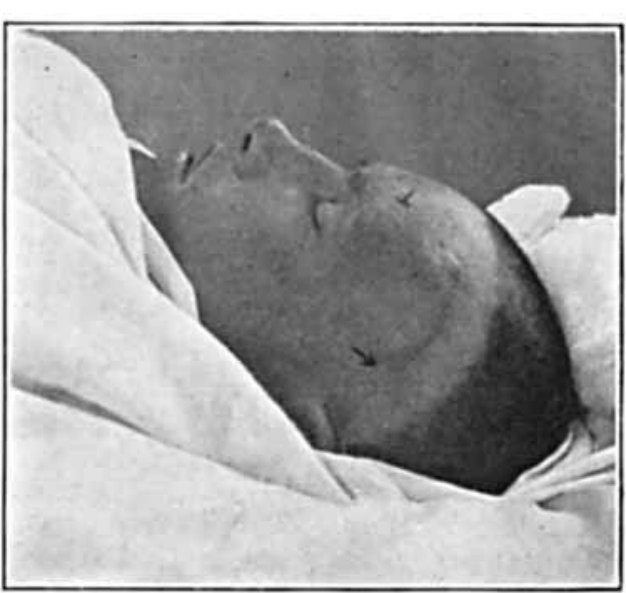

FIC. 78.-Case 6. Seven days after operation. cision. Removal of fracture en bloc (Fig. 77 ). Wound one inch in length in dura, with extensive laceration of the cortex. Wound sutured with glove-rubber drain. Healed uneventfully (Fig. 78).

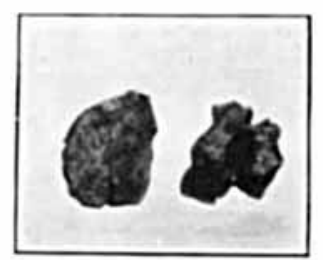

FIC. 79.-Case 7. Fracture removed en bIoc. Showing fragment in outer table, and depressed and separated portion of inner table.

Case 7.--Pte. J. T. Admitted two days after injury, with small ragged wound in left occipital region: no abnormal signs on neurological examination. 
$X$-ray Report.-Small metallic fragment in outer table. Detached fragment of inner table. operation.-Removal en bloc of fracture. There was a complete detachment of a portion of inner table (Fig. 79). This fragment had lacerated the dura. The wound was sutured and healed uncventfiully.

Case 8.-Pte. $\mathbf{E}$. In this case the projectile had fractured the occipital bone without causing much comminution, and was found superficial to the dura, in which there was a small laceration (see Fig. 80). It was curious that a velocity sufficient to cause a clean penctration of the skull

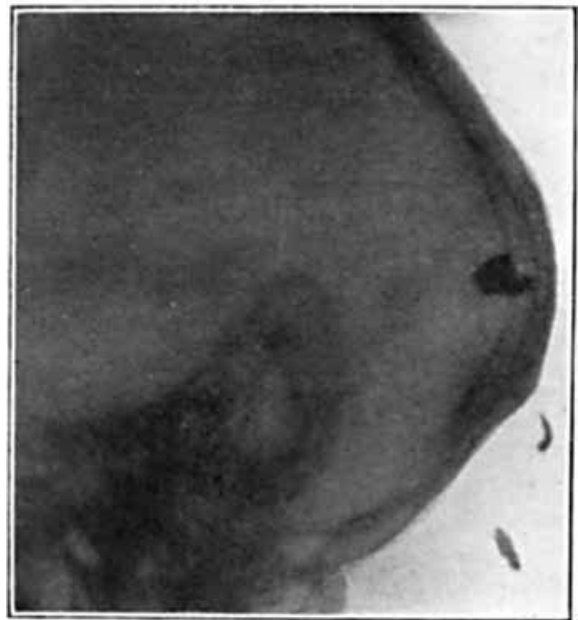

w1. 8).-Case 8. Penetration of projectile without comminution. failed to carry the projectile into the brain.

In the following case the condition was complicated by a middle meningeal hæmorhage. An indriven fragment had torn the dura, lacerating at the same time the anterior branch of the middle meningeal artery.

Case 9.-Pte. G. K. Admitted six hours after injury, having a ragged wound in the left temporal region.

Neurological Examination.--Patient stuporous. Right hemiplegia present. Left pupil smaller than right.

Operation.-- Wound excised, and depressed fracture of squamous temporal bone removed. Iarge extradural clot evacuated. Laceration of dura and partial division of anterior branch of middle meningeal artery. Artery ligated and dura sutured. There was good expansion after the removal of clot. Wound sutured with glove-rubber drain. Healed by first intention. Evacuated to base three weeks later. Hemiplegia subsided.

The next case is of interest in that a large dural defect was repaired by a graft taken from the temporal fascia. This was done because there was only a superficial injury to the cortex, and it was thought that in this way it might be possible to avoid an extensive cortical adhesion.

Case 10.- Gnr. B. Admitted five hours after injury.

On Admission.-Small superficial wounds of right shoulder, right hand, and left ankle. Glancing wound in left parietal region, and a larger, more ragged wound in right parietal region. Patient states that he was unconscious for a few minutes; but on admission he was alert and exhibited no abnormal neurological signs.

operation.--There was a depressed fracture in the left parietal region, which was removed. On the right side there was a depressed fracture of the parietal bone. The fragments had caused an extensive laceration of the dura, 1 by $1 \frac{1}{2}$ inches in extent. There was only a superficial laceration of the cortex. A graft taken from the temporal fascia was tucked in under the dural edges and sutured in place. The other wounds were excised.

Subsequently the ankle wound suppurated, and two days later superficial infection oceurred in the head wounds. This soon subsided, and the patient was evacuated.

\section{Group $I$. -WOUNDS, USUALLY OF GUTTER TYPE, WITH DEPRESSED BONE FRAGMENTS DRIVEN INTO BRAIN.}

These wounds are usually of a tangential nature, and are frequently accompanied by severe brain injury.

Velter ${ }^{10}$ states that prognosis is particularly grave in tangential wounds, for, though the wounds themselves are apparently benign, the deep lesions may be considerable.

It would be more correct to state that the post-operative prognosis depends entirely on the operation. It is necessary to spend much time in a gentle search for all the indriven bone fragments, however minute these may be. If this complete removal be successfully performed, the patient will almost invariably get well. Cases in this group should recover, and failures are usually to be attributed to some defect in operative 
technique. Naturally, the time which has elapsed since the infliction of the wound must influence the result. In some cases operated upon at the base, most formidable infection was demonstrated; but even in these cases successful results were obtained after careful cleansing of the wound and packing with B.I.P.P. gauze.

The following case demonstrates the difficulties attending successful treatment of cases of this group.

Case 11.-Pte. G. $\Lambda$. Admitted four days after the injury.

On Examination. Lacerated wound in the left frontal region, through which projected offensive brain tissue. The patient answered questions in an irritable manner, frequently incorrectly. No other abnormal neurological signs were discovered. $\boldsymbol{X}$-ray showed fracture of left frontal bone, with considerable loss of substance; indriving deeply

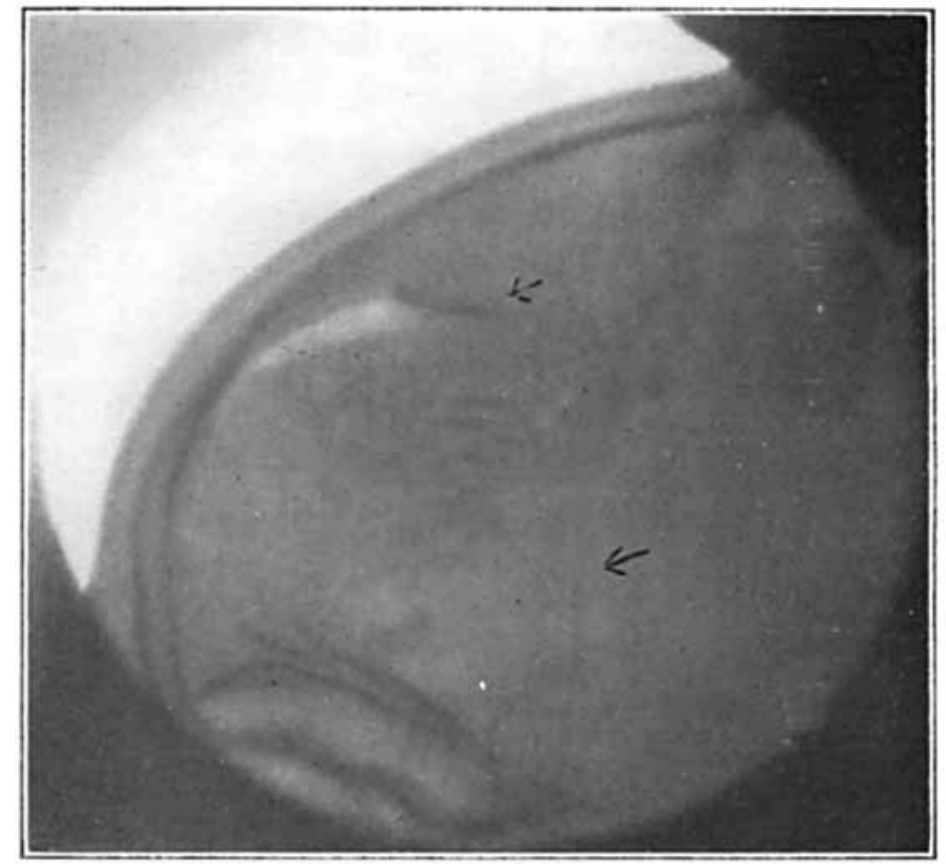

FIG. 81.- Case 11. Extensive indriving of frayments ints frontal lobe. into the frontal lobe of numerous small fragments (Fig. 81).

Operation.- The fracture was removed en bloc. There was an oval defect in the frontal bone,

A. reconstituted. P. Onter table iragments.

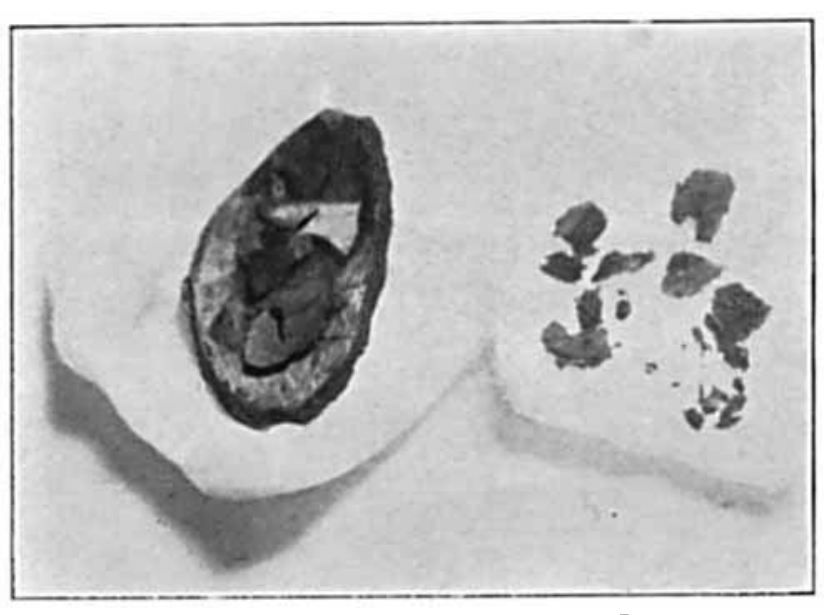

II: 82.-Case 11. En bloc removal of fracture. A. Inner table ronghly

2 inches long by $\frac{3}{4}$ inch broad (Fig. 82). The subsequent search for bone fragments lasted for one hour. After these had been removed, the wound was freely irrigated and the skin sutured in two layers over a B.I.P.P. pack. The pack was renewed on the third day and removed on the sixth day. Healing was 1111eventful.

Bacteriological Reporl (culture from indriven fragments).-Anaerobic bacilli, type $B$. Welchii, and type $B$. sporogenes, Staph. aureus, and the streptococci, short chains. The successful result, despite this bacterial infection, is to be attributed to the time spent in ensuring complete cleansing of the cerebral wounds.

In the following case it was necessary to excise a large ragged wound by the tripod incision. In this case there was also a hemiplegia, which is rapidly disappearing.

VOL. VII.-NO. 25 
Case 12.-Pte. T. M. B. Admitted thirty-six hours after infliction of wound.

On Admission.-Patient stuporous. Left hemiplegia present. The wound was lacerated and dirty, and contained numerous small metallic fragments.

Operation.-Excision of wound, removal en bloc of depressed fracture. Four bone fragments were driven deeply into the cortex. When replaced, these

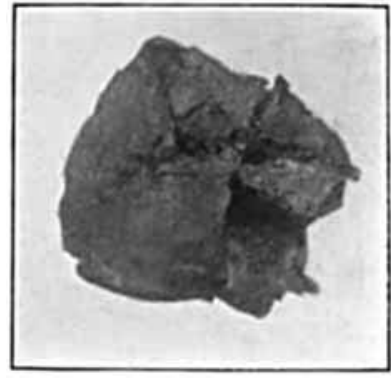

FIG. 83.-Case 12. Mosuic of inner table. liraginents replaced.

reconstituted the mosaic of inner table (Fig. 83). The wound was sutured over a B.I.P.P. pack, and healed without incident (Fig. 84).

Six weeks after the operation, voluntary motor power returned in the muscles of the thumb. The patient then rapidly regained movement in both upper and lower limbs, and three months after the operation was able to walk.

The next case illustrates an occipital lesion with hemianopsia.

Case 13.--Pte. A. G. F. Admitted twenty-four hours after injury.

On Admission.-Patient stuporous. No other abnormal signs on neurological examination before operation. $X$-ray plate showed three fragments driven into occipital lobe.

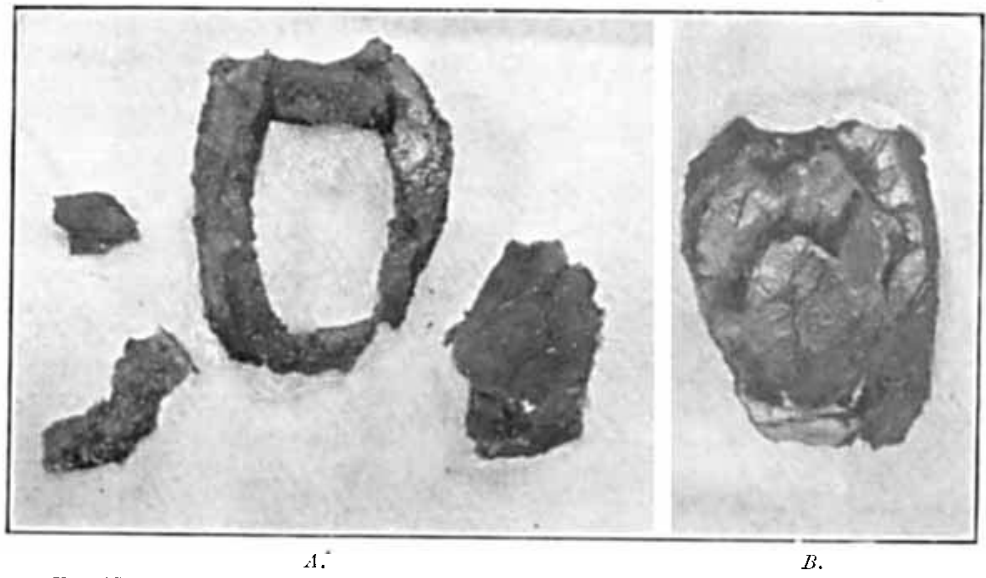

IiT. 85.--Case 13. A. Outer table and fruginents. $B$. Inner table reconstituted.

Operation.--Excision of wound. Removal of fracture en bloc. Three bone fragments removed from brain. When placed in position these accurately restore the continuity of the bone (Fig. 85). The wound was sutured with glove-rubber drain and healed by first intention.

The patient would answer questions two days after the operation, when a left hemianopsia with contraction of the right fields was demonstrated. Accurate investigation was impossible at this stage. Six wecks later a quadrant defect remained (Fig. 86). 


\section{GUNSHOT WOUNDS OF THE BRAIN}

Cerebellar and temporal lesions have, it is stated, a better prognosis than is the case with wounds nearer the vertex. This is probably due to the fact that in these cases the cerebral wounds are well covered by a muscular layer, and their reinfection from the skin is not so frequent.
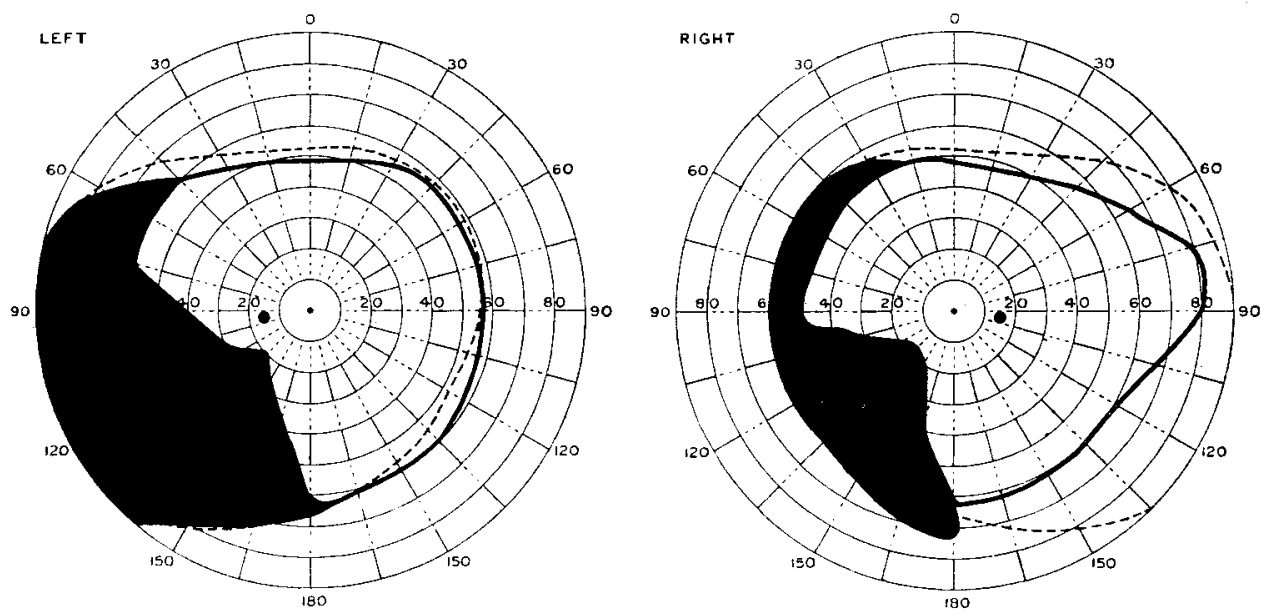

lic. 86.-Case 13. Vistal field six weeks aiter operation.

Case 14.-Pte. W. E. G. Operation six hours after infliction of wound.

On Admission.-- Patient stuporous. Glancing wound of left cerebellar region.

operation.-Wound excised. Fracture of occipital bone immediately lateral to torcular IJerophili exposed. The fracture was removed en bloc. There was no sinus injury, but a wound in the dura, 1 inch in length, over the cerebellum. Several small fragments were removed from the cortex. After irrigation, the dura was sutured with fine catgut. The muscles and skin were then sutured with glove-rubber drainage. Healing by first intention.

Progress report four months later : No abnormal signs.

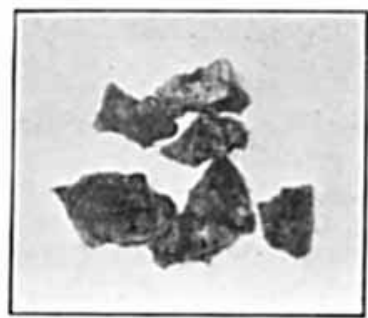

FIG. 8 i.--Case 15. Tragments remored from temporal lobe.

Case 1.5.-Pte. H. B. T'emporal lesion. Admitted two days after injury.

On Admission.--Patient states that he was unconscious for about one hour, and can remcmber walking to the dressing station. Lacerated wound in left temporal region, with small hernia cerebri.

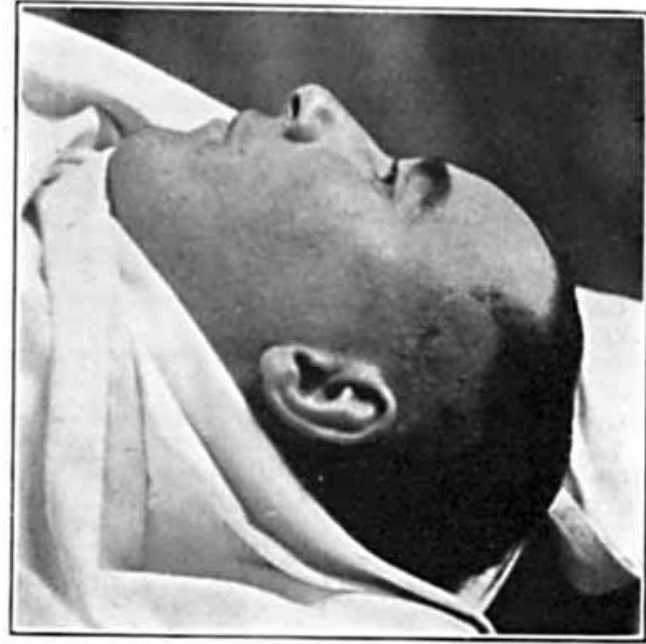

Fia. 88.-Case 15. Wound fourteen days after operation.

operation.-Wound excised by curved incision. Burr opening at edge of fracture, which was then enlarged by a rongeur, so that the wound in the dura was complctely exposed. Numerous fragments were removed from left temporal lobe (Fig. 87).

The wound was sutured without drainage, and healed well (Fig. 88). 


\section{THE BRITISH JOURNAL OF SURGERY}

In the following case there was a large bone defect in the right frontal region, extending almost to the supra-orbital margin, from which fissures radiated in various directions.

Case 16.-Sgt. W. P. Admitted three days after injury.

On Admission,-Large wound in right frontal region, with offensive hernia cerebri. Patient was extremely restless and irrational. Gencral condition poor. Temperature $103^{\circ}$; pulse-rate 120. $X$-ray report: Fracture, with fissuring in frontal bone (Fig. 89).

Operation.-Patient was so restless that a general anasthetic was administered. Wound cxeised by curved incision. Burr opening at margin of fracture, which was then enlarged to expose

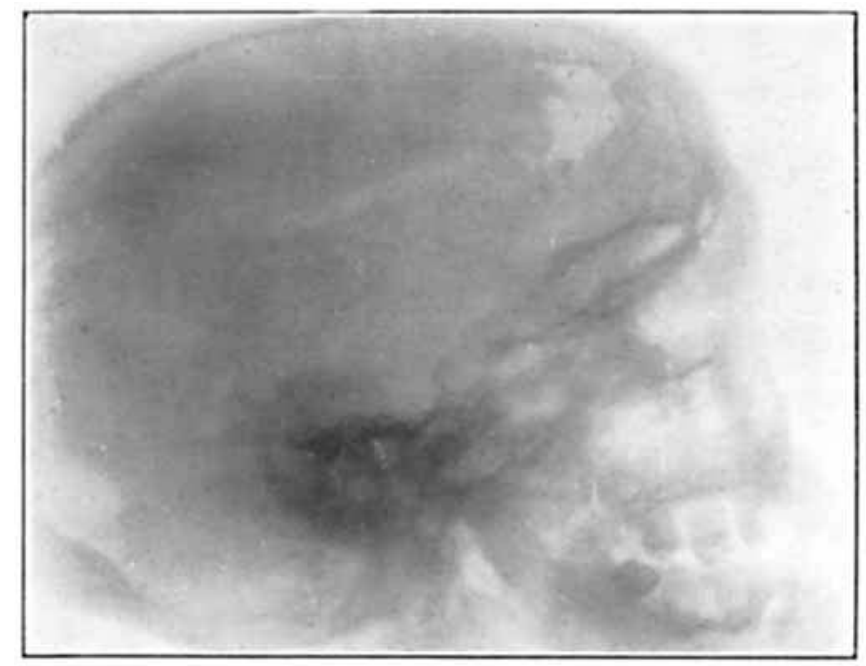

IIG. 89.-Case 16. Turre defect in frontal bone, with fissuring.

the dural edge. There was a very extensive Iaceration of the right frontal lobe, without many ndriven fragments. Wound sutured over a B.I.P.P. pack.

Bacteriological Report.-Anaerobic bacilli ; short-chain streptococci and staphylococci.

No hernia cerebri occurred, but there was some superficial infection of the wound, one part of which healed by granulation. Two months after the operation, mental condition was not quite normal, but had improved considerably.

Fatal Cases. - In the first of these cases a piece of wire had been driven some distance under the scalp from the wound. This track was not completely excised, and was responsible for a rapidly-spreading infection.

Case 17.--Pte. C. Y. Operation was performed ten hours after infliction of wound.

On Admission.-Gutter wound of right temporal region, with several metallic fragments in the wound, $\boldsymbol{X}$-ray showed tangential fracture of squamous temporal region, with fissuring extending to the base of the skull.

Operation.-Wound excised. Piece of wire 2 inches long embedded in scalp. This wound was partly excised, the remainder being curetted and treated with B.I.P.P. The fracture was enlarged by a rongeur to expose the dural edge. The wound in the brain was irrigated after removal of loose fragments of bone. Sutured, with glove-rubber drain. Infection spread from site whence the wire had been removed, and involved the whole wound. A soft fungus rapidly developed, and the patient died five days after the operation.

Autopsy.- No bone fragments were found in the brain. Infection apparently spread from the superficial part of the wound.

In the next case death was due to an incomplete removal of bone fragments, which were small and scattered. This case was operated upon before it was realized that it was necessary to spend a considerable time in the search for these fragments.

Case 18.-Pte. L. C. Operation performed thirty-six hours after the infliction of the wound.

On Admission.-Patient stuporous and restless. Large ragged wound in the right temporal region. $X$-ray report states: Tangential fracture, with numerous indriven fragments. 


\section{GUNSHOT WOUNDS OF THE BRAIN}

Operation.-Removal of fracture en bloc (Fig. 90). Small fragments and a large blood-clot removed from temporal lobe; wound sutured, with glove-rubber drain. The general condition was improved on the following day, but subsequently a hernia cerebri appeared, the patient had many convulsive attacks, and death occurred on the sixth day.

Autopsy.-Large disintegrated area in the right frontal lobe, in which there were severa unremoved fragments. (Brain preserved for examination.)

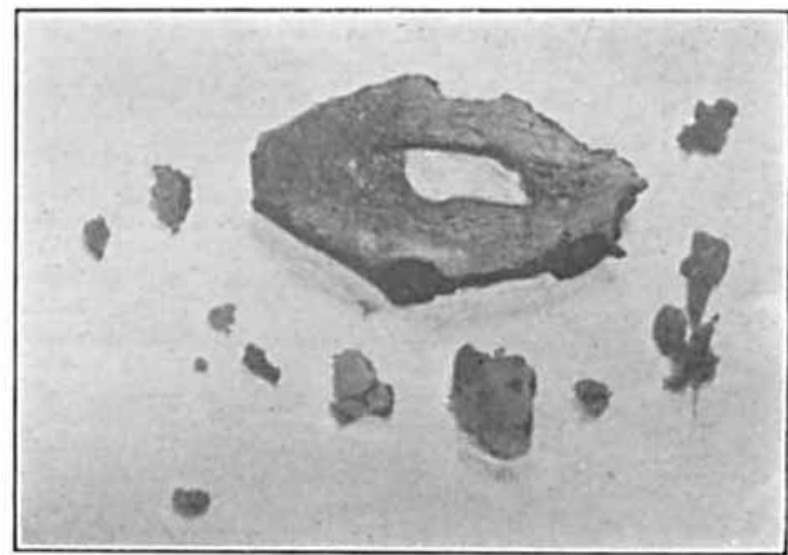

FIG. 90.-Case 18. Fracture of bone fragments. Incomplete removal demonstrated at autopsy.

The following case illustrates the third factor, namely, the influence on the result of delay in operating.

Case 19.-Pte. B. This case was not admitted until the fifth day after the injury. The wound was in the right post-parietal region and was grossly infected. The temperature was 104 on admission; pulse-rate 130 . The usual operation was done, but the infection spread, and the patient died thirty-six hours later. 'There was no autopsy.

The following conclusions are to be drawn from these fatal cases: (1) Excise the wound completely ; (2) Remove all indriven fragments ; (3) Operate as early as possible after the infliction of the wound.

\section{Group III.-WOUNDS OF PENETRATING TYPE WITH LODGEMENT OF PROJECTILE AND BONE FRAGMENTS.}

In this group of injuries there is typically more destruction of cerebral tissue than in Group II. In the latter group the whole force of the impact is not directed into the brain. This is demonstrated in the accompanying diagram (Fig. 91). In Group III the

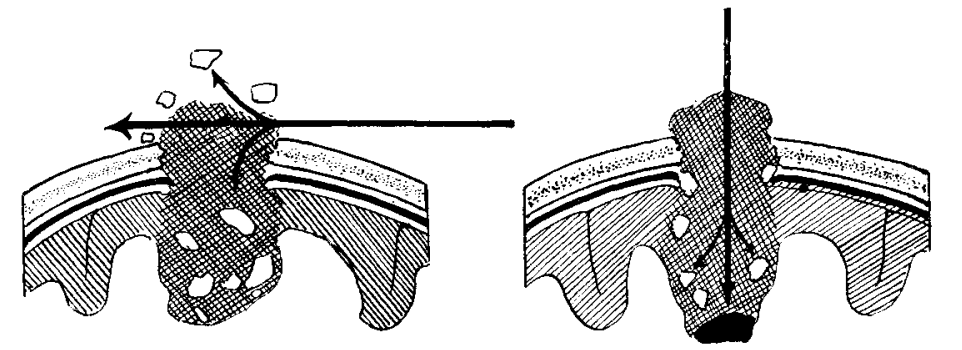

FIG. 91.- Diagram to illustrate type of injury and direction of foree in Groups $I I$ ans $I I I$.

technical difficulties are further increased by the problem of removal of the projectile. It. must be emphasized that the more severe types of tangential injury may cause greater 
cerebral laceration than is present in certain cases in this group, and that the prognosis is largely dependent upon the extent of the laceration.

In the following case the projectile was easily accessible, and was removed.

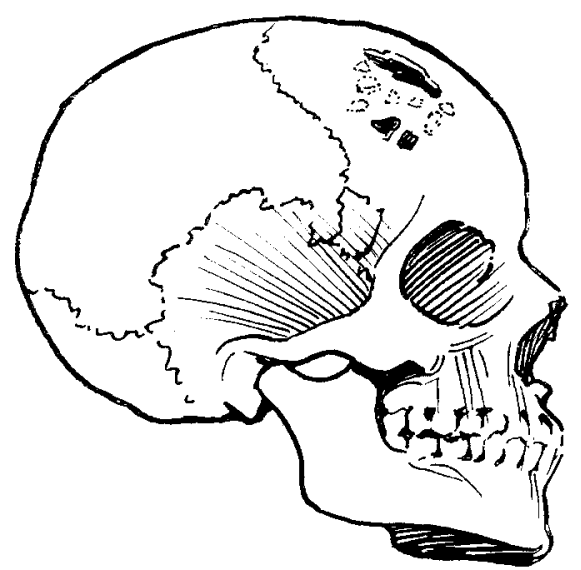

Hia. 92,- Case 21\%. Diazram of injury.

Case 20.-Sgt. D. Admitted two days after injury. Irregular wound, with brain tissue exuding in the right frontal region.

On Admission.-Patient unconscious. No localizing neurological signs. $X$-ray showed fracture of frontal bone on the right side. Two metallic fragments in the frontal lobe (Fig. 92).

operation. Wound excised by tripod incision. Fracture removed en bloc. Bone fragments and projectile removed from the brain. B.I.P.P. pack, wound sutured. Pack left in situ for three days. The wound healed well (Fig. 93).

Patient regained consciousness on the day following the operation, and became very restless and excitable for some four days afterwards. Two months later there were no complications and the man's mental condition was normal. It is of interest to note that in this case and in Case 16, where the injury was in the right frontal region, the mental disturbance was much more marked than in Case 11, where there was a left frontal-lobe injury.

In the next case no attempt was made to remove the projectiles, which were deeply situated in the middle fossa.

Case 21.-Rfm. C. Operation twelve hours after the infliction of the wound.

On Admission.--Patient unconscious. Left hemiplegia present. Entrance wound in the right frontal region. $\boldsymbol{X}$-ray plate shows several metallic fragments lying lateral to the pituitary fossa on the right side.

operation.-The wound was excised, and disorganized brain and bone fragments were removed. Wound drained by a paraffin-gauze strip.

One month after the operation the wound had healed. The patient would answer questions rather stupidly. Voluntary movement had returned at the hip- and knee-joints, but not at the ankle-joint or in the upper limb.

In the next case the projectile had lodged in the wound and had driven the bone fragments deeply into the brain Though there was no intracerebral projectile, the character of the injury warrants its inclusion in this class. This case was also of interest in that a 'sinus syndrome' was present, despite the fact that no gross lesion of the sinus was demonstrated.

Case 22.--Pte. D. H. Admitted thirty-six hours after wound.

On Admission.-Conscious, answers questions, but resents interference. Large lacerated wound in the parietal region extending across the mid-line. Fracture of the right parietal

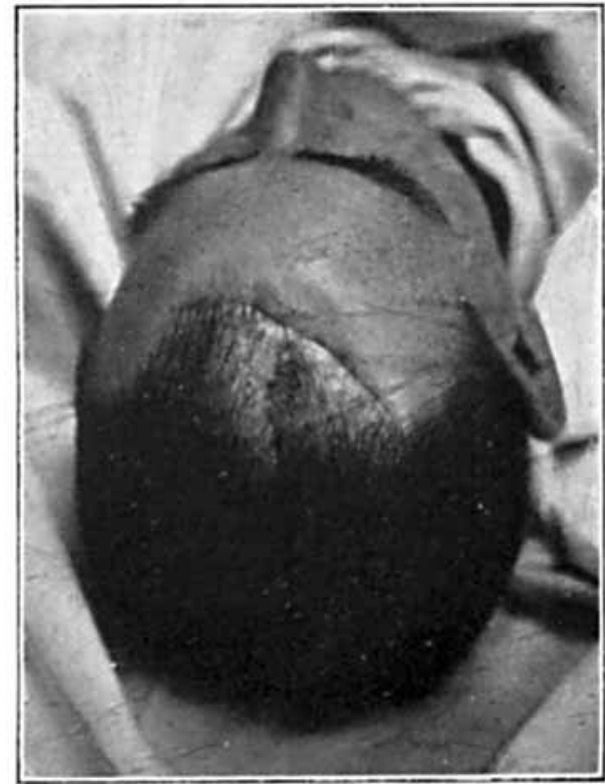

FIs. 93,--.-Case 20. Wound four weeks after operation.

bone. X-ray report states : deep indriving of fragments. No voluntary power in lower limbs ; weakness of right upper limb. Deep reflexes increased in these limbs. Superficial reflexes not elicited. Double extensor plantar response.

operation.-Excision of wound. Removal of fracture en bloc. Fragments removed from 


\section{GUNSHOT WOUNDS OF THE BRAIN}

the brain. There was no obvious sinus injury, and the dural wound was completely on the right side of the mid-line. The wound was treated with B.I.P.P. and sutured. A small hernia developed ten days after operation, but subsided in three weeks, when the wound rapidly epithelialized.

A subsequent $x$-ray examination revealed the presence of a small bone fragment, which was doubtless responsible for the delay in healing. As the patient continued to improve, the fragment was not removed.

Three months after the operation, range of movement was normal in the right upper limb, though the power was less than in the left upper limb. Spasticity of both lower limbs was pronounced, but voluntary movement through almost normal range had returned at both hipand knee-joints. No movement was present in the muscles of legs or feet. The deep reflexes were exaggerated, and $\mathbf{R}$ and $\mathrm{L}$ patella- and ankle-clonus were present. There was no sense of muscle position at the ankle- or toe-joints, but movement at the hip- and knee-joints was correctly perceived. Localization of touch was not accurate. The mental condition was normal.

The next case demonstrates the immediate recovery possible in apparently hopeless cases. There were two penetrating wounds in the left parietal region and a depressed fracture of the frontal bone. The bacteriological infection was most formidable.

Case 23.- Pte. H. Admitted two days after infliction of wound.

On Adrission.- Two penetrating wounds in the left parietal region; small glancing wound in the right frontal region. X-ray report says: two small metallic fragments at the base of the brain on the left side.

Operation.-Wounds and fractures in the parietal region excised. Small bone fragments removed from the brain. Wound irrigated. Sutured over a B.I.P.P. pack. Wound of frontal region excised. Depressed fracture removed en bloc; no dural penetration. Wound sutured.

Bacteriological Report (culture from indriven fragment).--Anaerobic bacilli, type $\boldsymbol{B}$. Welchii. Streptococci, long-chain type; staphylococci ; micrococei, type tetragenus. Bacilli, other types.

The wounds healed with only one area of superficial suppuration. Fourteen days after the operation the patient, who had been very noisy, became quieter, and would answer questions rationally. One week later, in response to requests from relatives, he was evacuated to England, as a further improvement had taken place in his mental state.

Fatal Cases.--These cases may be divided into two groups: (1) Patients comatose on admission, who died shortly afterwards without regaining consciousness. The condition

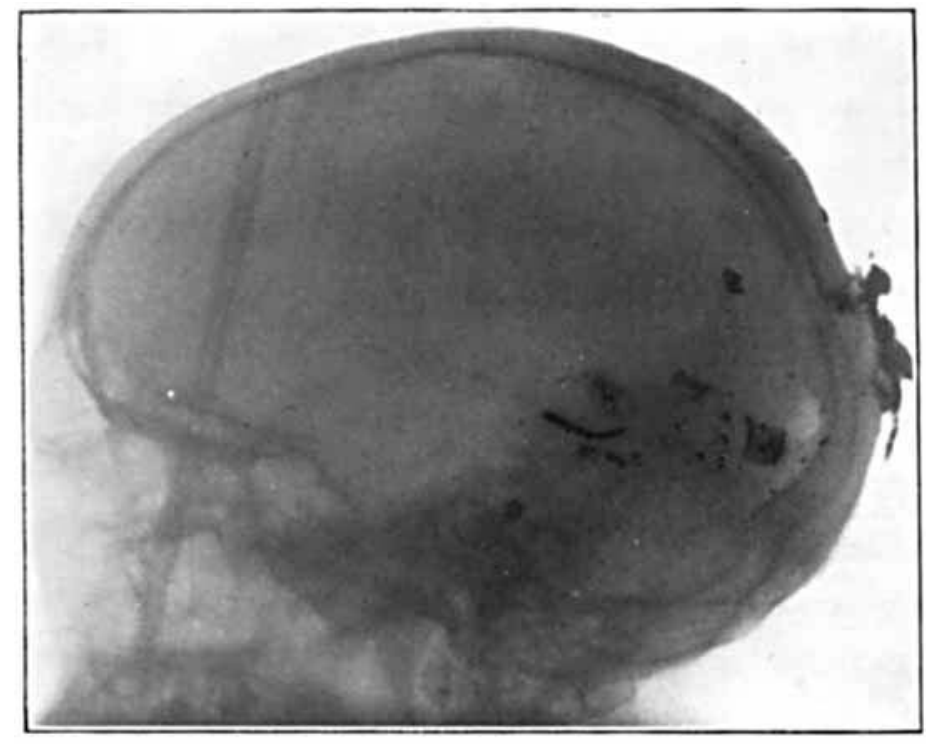

Figr. 94.-Case 25. Numerous intracranial projestiles.

of these patients did not admit of serious surgical treatment. (2) Patients in whom infection of the wound was present, and who died from cerebritis at a variable period after the operation. 
Of the 6 fatal cases, 3 are included in each group. Two cases will be quoted. In the first, recovery would have followed earlier operative intervention; whilst in the second, the multiplicity of the foreign bodies and the extent of the cerebral injury rendered effective operative treatment very difficult.

Case 24.-.Pte. J. B. 'This man had been lying in a shell-hole in 'no-man's land' for two days, and on admission was very exhausted. There was a small, very infected wound of the left parietal region.

$X$-ray Report.-Fracture of left parietal bone. Metallic fragment 1 inch from surface.

Operation.-Wound and fracture excised. Gas gangrene was present in the brain. The projectile was removed and the wound cleaned, but a cerebral hernia developed, and the patient died two days after the operation.

Case 25.-L.-Cpl. S. S. Admitted thirty-six hours after injury.

On Admission.-Large wound in occipital region containing numerous picces of metal. Patient stuporous.

$X$-ray Report.-A large number of fragments of metal passing forwards superficially in the right occipital cortex (Fig. 94).

Operation.--The fragments were not completely removed, and the patient died of acute cerebritis two days later.

\section{Group $I V$.-WOUNDS INVOLVING PENETRATION OF THE VENTRICLES.}

There have been no certified recoveries in any case of this type. Cushing has had a similar experience. One case survived for the extraordinarily long period of fourteen

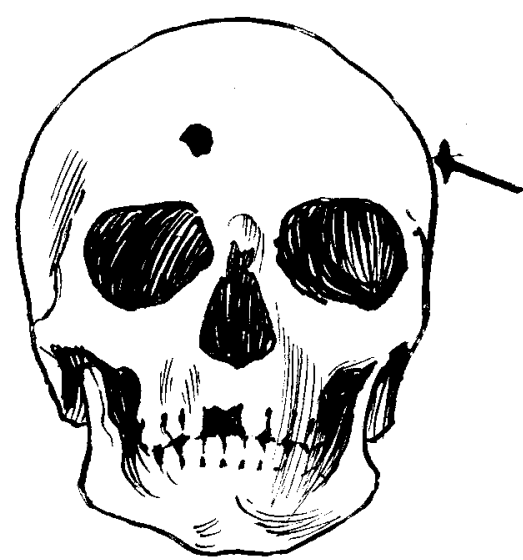

FIG. 95.-Case 26. Diagtam of course of projectile.

Case 27.-Pte. R. M. Admitted two days after wound.

On Admission.-Unconscious. Small entrance wound above left ear. Considerable laceration of the pinna. $X$-ray shows foreign body near the mid-line in the left frontal lobe.

Operalion.-Decompression at the site of entrance. Projectile not removed. The patient remained unconscious for five days.

Autopsy.-There was a considerable meningeal infection around the cortical wound. (Brain preserved for investigation.) days; another lived for seven days; but the remainder all died soon after admission.

Case 26.-Sgt. D. Admitted eight hours after infliction of wound.

On Admission.-Comatose. Babinski reflex elieited on both sides. Superficial abdominal reflexes absent. Small wound of entry above left ear. $X$-ray showed a projectile in right frontal lobe (Fig. 95).

Toperation. - Decompression at sitc of entrance wound. Some bone fragments removed from track. Death twenty hours after operation.

Autopsy.-The projectile, a piece of high-explosive shell, had traversed the body of the left lateral ventricle and the anterior horn of the right lateral ventricle. There was considerable hamorrhage along the track, and ventricular sepsis had occurred.

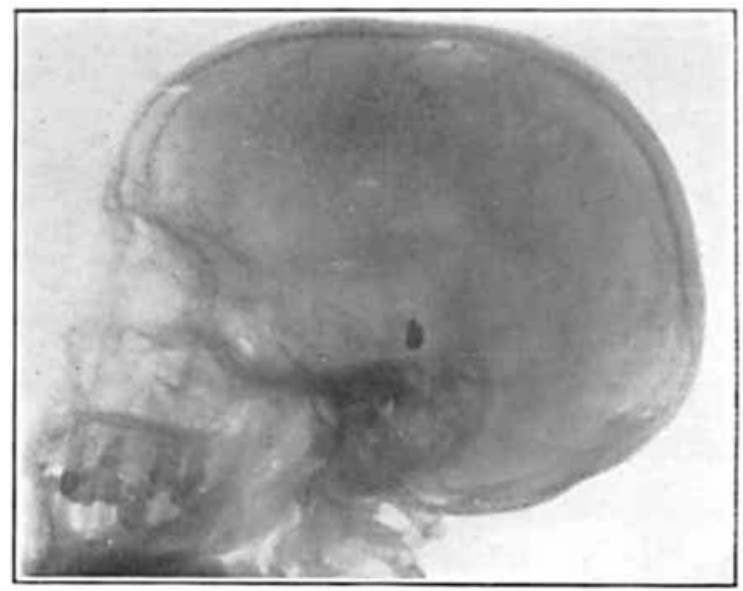

FIa. 96,-Case 28. Fracture of vertex. Trojectile at base of skull. 


\section{GUNSHOT WOUNDS OF THE BRAIN}

Case 28.-Pte. W. G. M. Admitted six days after injury. Casualty clearing station notes: "Compound fracture of skull, with hernia cerebri. Right hemiplegia. Comatose. Evacuated to the base."

On Admission. - Large lacerated wound in mid-line, brain tissue exuding. $X$-ray shows fracture of vertex, metallic fragment at base of brain (Fig. 96).

Operation. - Cleansing of track after removal of wound and fracture en bloc. Glove - rubber drain. A cerebral hernia (Fig. 97) developed after the operation, but the patient lived for eight days.

Bacteriological Report.-Anaerobic bacilli, long-chain streptococci, and staphylococci.

Autopsy. - The projectile had penetrated the third ventricle, and there was an intense infection of the meninges, the cerebral tissues, and the ventricular system.

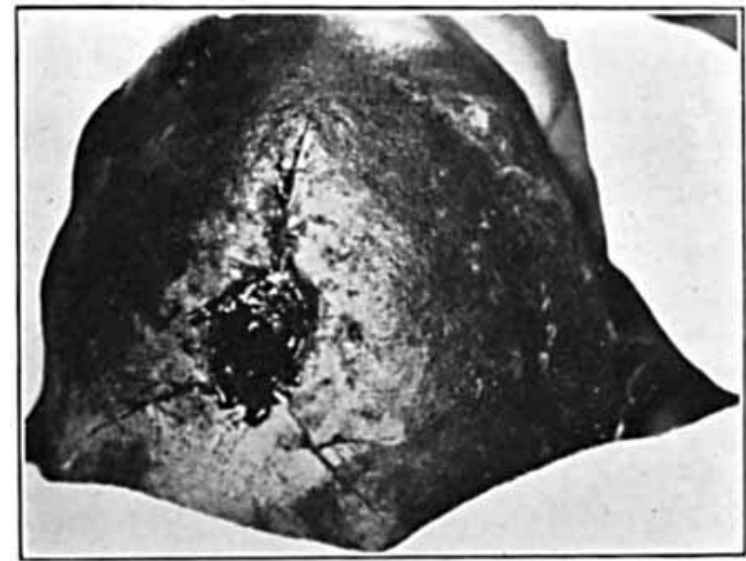

Ys. 97.-Cuse 28. Cerebral hernia aiter operition.

\section{Group $V_{--}$-WOUNDS INVOLVING BOTH THE BRAIN AND AN AIR SINUS.}

In this type of injury the difficulties of treatment are increased by the risks of infection from the air sinus. Of the four cases of this group the frontal sinus was involved in two, whilst in the remaining cases the ethmoidal air-cells were fractured by the projectile. In the frontal-sinus cases the cerebral injury was not extensive, and both patients recovered. The ethmoidal cases, on the other hand, died of cerebromeningitis.

Frontal Sinus Injury.-The following case will serve as an example :-

Case 29.-Pte. J. I. Admitted six hours after injury.

On Admission.-Vertical wound in the right supra-orbital region. Mental condition normal; no abnormal signs on neurological examination.

Operation.--The wound was excised and the fracture exposed. It involved the anterior wall of the frontal sinus. A burr opening was made above the sinus and the dura exposed. The anterior sinus wall was removed, thus revealing a projectile embedded in the posterior sinus wall and projecting into the dura; it was removed, together with some bone fragments. The dural wound, $\frac{1}{2}$ inch long, was sutured, and the scalp wound closed with rubber-glove drainage. It healed uneventfully, and the patient was evacuated to the base quite well three weeks later.

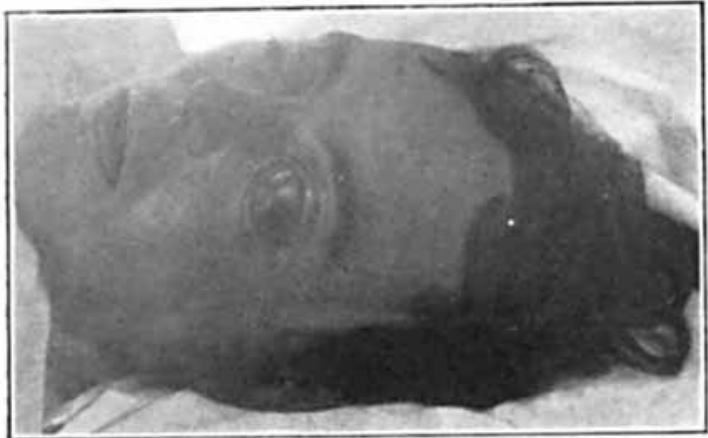

FIt. 98.-Case 30. Wound of entrance. Exophthalmos.

Suture of the dura is indicated in this type of case, as thereby the risk of cerebral infection is diminished. Owing to an early operation it was fortunately possible in this case.

Ethmoidal Cases.-In the first case of this type the projectile had traversed the orbital cavity, causing an arterio-venous aneurysm of the ophthalmic vessels and a pulsating exophthalmos; then, passing through the lateral mass of the ethmoid bone, it had lodged in the opposite frontal lobe, whence it was removed. Death from meningitis occurred seven days after the operation.

Case 30.-Pte. G. W. Admitted four days after the infliction of the wound.

On Admission.- The patient was conscious, and there were no localizing neurological sign 
The wound of entrance was just above the left zygoma ; there was a pulsating exophthalmos of the left eye (Fig. 98). $\quad X$-ray showed fractures of the lateral wall of the orbit, the lateral mass of the ethmoid, and the cribriform plate; the projectile had lodged in the right frontal lobe (Fig. 99).

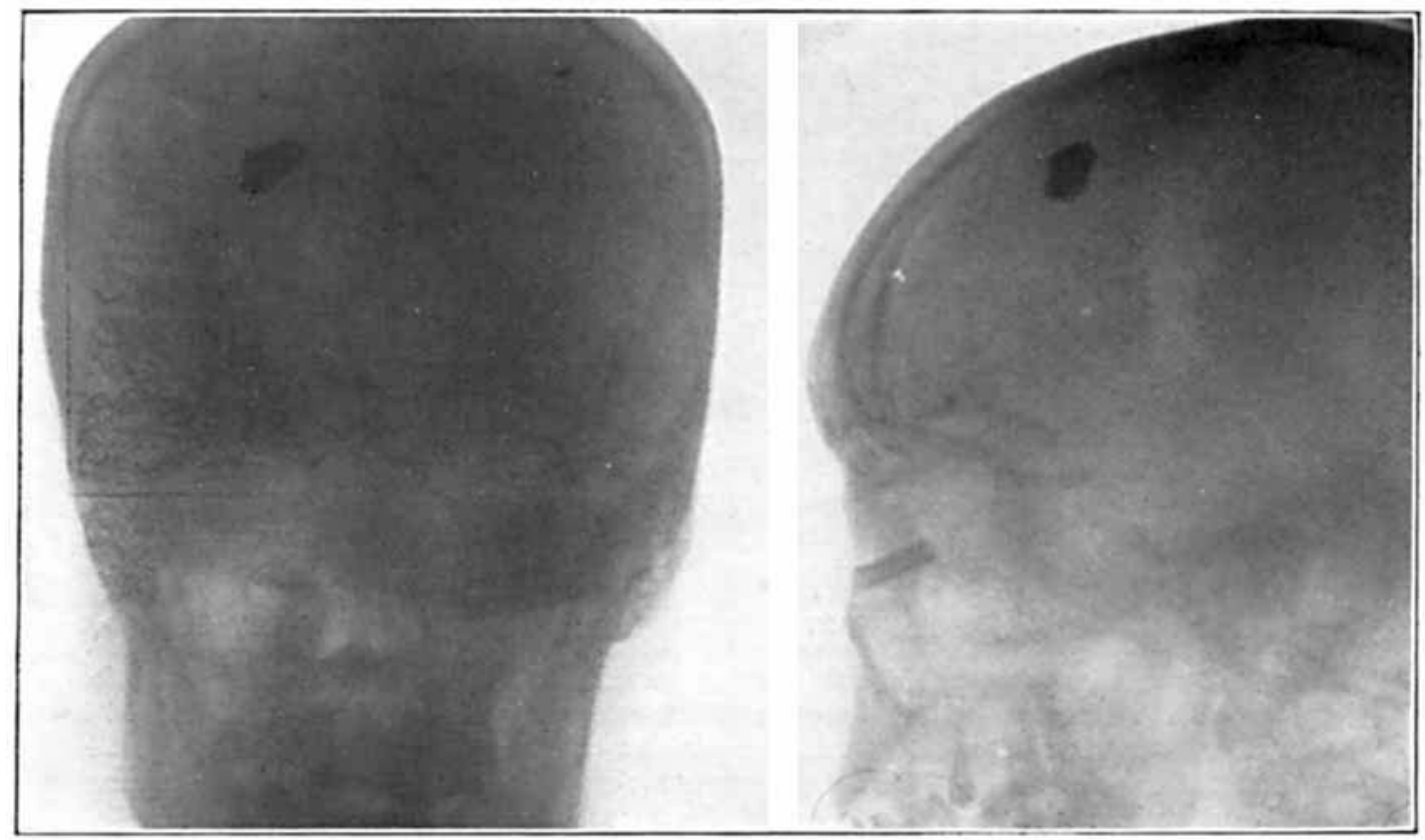

Fig. 99. Case 30. Antero-posterior and lateral views of projectile.

Operation.--This was performed in two stages. First stage: General anæsthesia. Left common carotid artery exposed and temporarily controlled. Left eye enucleated. Strong pulsation palpable in the orbital cavity. Wound of entrance excised and outer wall of orbit removed. The projectile had passed through the middle of the cavity. A hemostatic forceps was applied to the tissues at the apex of the orbit,

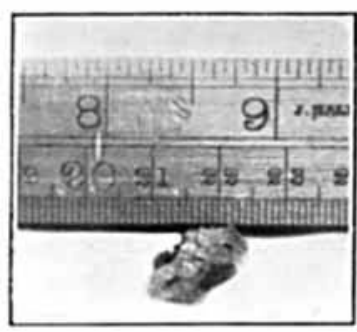

Fig. 100.-F'rojectile removed in Case 3 औ. and the contents of the orbital cavity were freely removed. A flavine pack was placed in the orbital cavity. The common carotid artery was not tied, and the wound in the neck was sutured. Second stage: Two days later the pack was removed and the forceps released; there was no hæmorrhage. The projectile was then localized by the apparatus devised by Captain Ferguson ${ }^{7}$. Under local anæesthesia the right frontal cortex was exposed, and the projectile, an irregular piece of high explosive (Fig. 100), was removed. The temperature, which was $101.5^{\circ}$ on admission, remained high. 'The patient became steadily weaker, and died five days after the operation.

Autopsy. - There was an extensive basal meningitis, which was most marked in the ethmoidal region, where the air-cells communicated with the meninges. The wound in the cortex through which the projectile had been removed was clean. The cavernous sinus was not injured; the vascular lesion had been entirely intra-orbital.

The next case is of interest owing to the size of the projectile, which weighed $121 \frac{1}{2}$ grms.

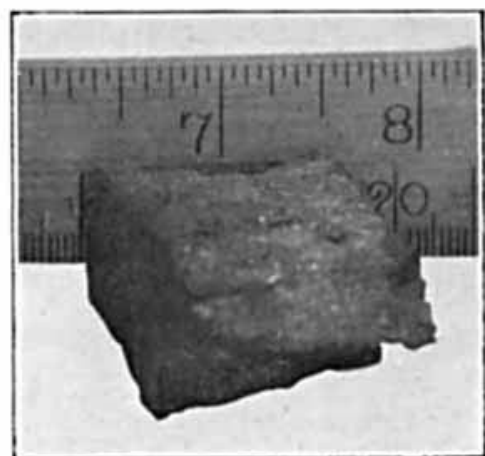

IIG. 101.-Case 31. Weight of projectile $121 \frac{1}{2}$ gr.ns. 
Case 31.--Pte. B. Admission twelve hours after injury.

On Admission.- There was a large entrance wound in the right temporal fossa. Marked proptosis of the right eye was present. The patient was stuporous.

Operation.-The wound was excised and a fracture of the temporal bone removed. The projectile (Fig. 101) had lacerated the apex of the temporal lobe, penetrated the orbit, and had lodged in the inner part of this cavity, penetrating the ethmoidal air-cells. It was removed, and the wound cleansed after enucleation of the eye. Drainage through the orbit. 'The patient improved for two days after the operation, but then signs of infection manifested themselves, and death from meningitis occurred on the sixth day.

\section{Group VI.-THROUGH-AND-THROUGH CRANIOCEREBRAL WOUNDS.}

Wounds of this type, as seen in hospital, have a more favourable immediate prognosis than is the case with lodging wounds. 'This may be' attributed to the fact that, as a general rule, only the more superficial types of throughand-through wounds survive to reach a hospital. In these cases, further, the track can be easily cleaned, and efficient drainage is provided by the nature of the wound.

There were six cases of this type in this series. Of these, only one died in hospital. Suppuration was present in two cases when they were evacuated, and unfortunately no subsequent reports have been received from these. The end-result is therefore in doubt.

Case 32.-Pte. C. G. H. Admitted three days after injury.

On Admission.-.-Small en-

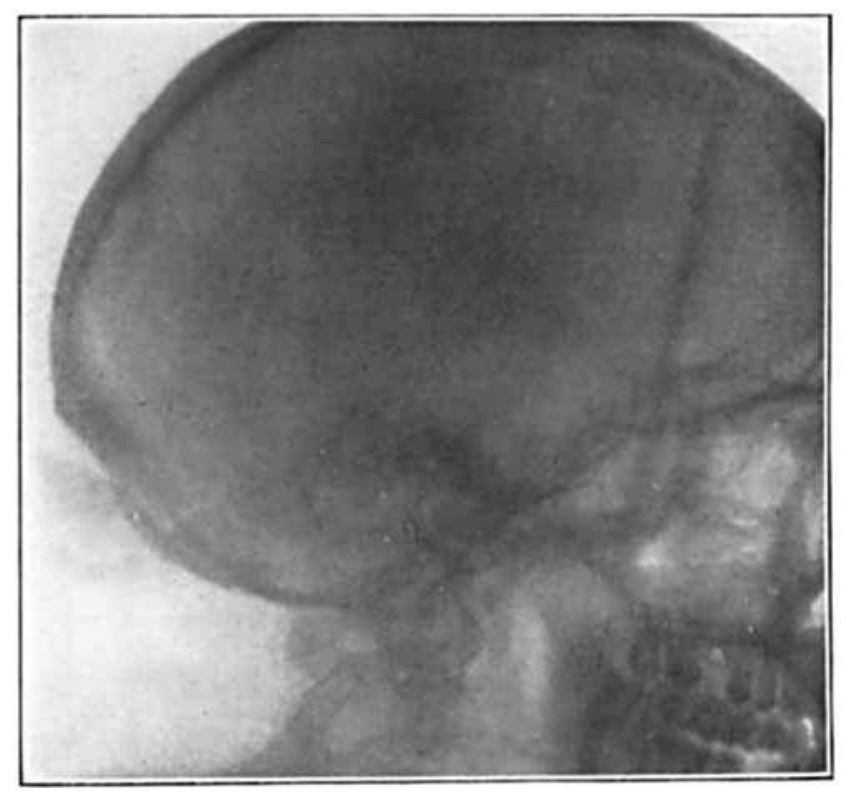

trance wound above and behind

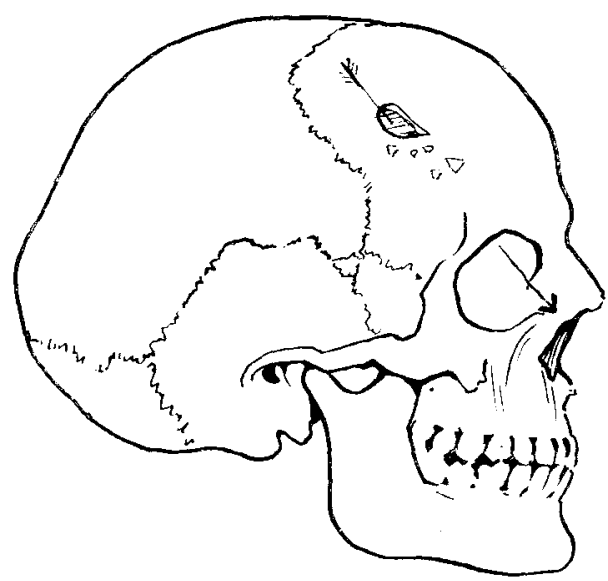

FId, 103.--Illustrating fronto-orbitsl wound.
FIx. 102.-Case 33. Exit wound in cerebellar region.

Ieft ear. Larger exit wound above and to the left of external occipital protuberance. The patient would answer his name, but was unable to give particulars or to frame any coherent sentence. He was very irritable. $X$-ray showed small indriven fragments at entrance wound. Explosive fracture at exit.

Operation.-Both wounds excised. Indriven bone removed from entrance wound. Exit wound cleaned. Suture, with glove-rubber drainage. Infection occurred at wound of entrance, which eventually healed without the formation of a hernia.

There was no interference with visual acuity or the visual fields, doubtless due to the fact that the wound involved only the outer surface of the occipital lobe. The aphasia soon subsided, and three weeks after the operation the patient's mental state was quite normal.

A striking illustration of the importance of complete removal of indriven fragments is 
afforded by these cases of through-and-through wounds. The actual cerebral laceration is frequently greater at the exit wound. But here bone fragments are absent, and healing occurs with much greater facility than is the case at the wound of entry.

Case 33.-. Pte. C. In this case there was a very marked explosive wound in the cerebellar region just to the left of the mid-line (Fig. 102).

This wound was exeised, and, despite the extensive cerebellar injury, healed without difficulty The entrance wound in this case was small, and there was only one indriven fragment, situated at the lateral border of the left lobe of the cerebellum.

In two cases the wound involved the frontal lobe and the orbit (Fig. 103). This type is more difficult; reinfection through the orbit is difficult to prevent. Both cases became infected after some days, and in one of these a hernia developed at the entrance wound; both were evacuated after six weeks, somewhat improved but still suppurating. These cases, therefore, cannot be regarded as successful. The operative technique employed was the usual cleansing of the entrance wound and removal of bone fragments, with removal of the eye and drainage through the orbit,

\section{Group VII.-WOUNDS INVOLVING INJURY OF A VENOUS SINUS.}

The operative technique has been improved by the adoption of the muscle-graft method of arresting hromorrhage, which was first introduced by the late Sir Victor Horsley, and which was certainly not the least of the contributions made by him to surgical knowledge. Hæmorrhage is more easily arrested by a muscle graft ; but a graft from the epicranial aponeurosis is more easy to obtain and is almost as efficient in its action.

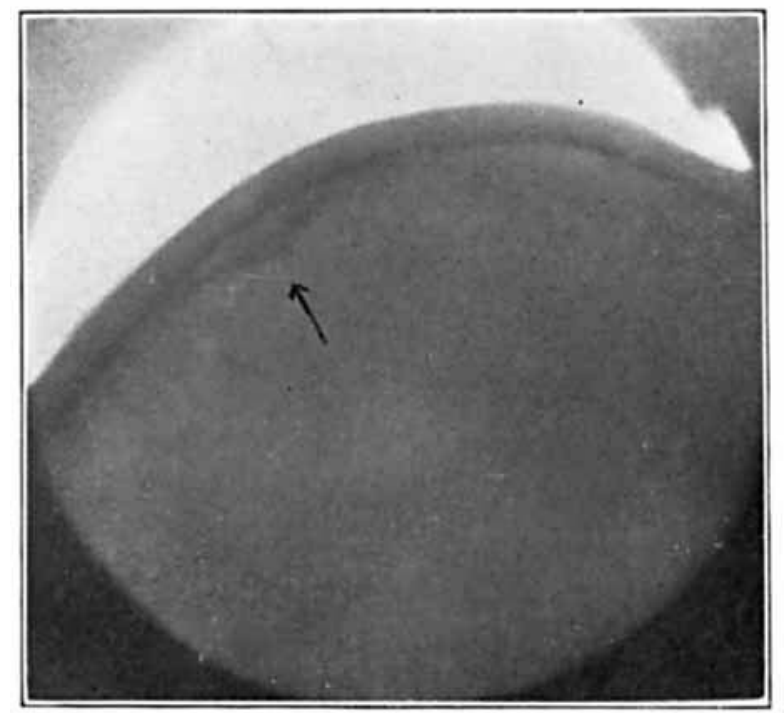

Fic. Int.-Case :34. Depressed fracture indicated by arrow.

Attention has already been directed to the importance of an en bloc removal of the fracture in cases where a sinus injury is suspected. In this series there were four cases of sinus injury, with no deaths. In no case was the sinus completely divided, and all were treated by the muscle or fascial method. In three cases the longitudinal sinus was involved ; in the remaining case there was a small tear in the lateral sinus.

Case 34.--Pte. J. S. Admitted two days after injury.

On Admission.-Large scalp wound passing transversely across the vertex in the post parietal region. No abnormal signs on neurological examination. $X$-ray showed a depressed fracture (Fig. 104). 
Operation.-Fracture removed en bloc (Fig. 105). The fragments of inner table had lacerated the longitudinal sinus, and free hamorrhage occurred on removing the fracture. This was success-

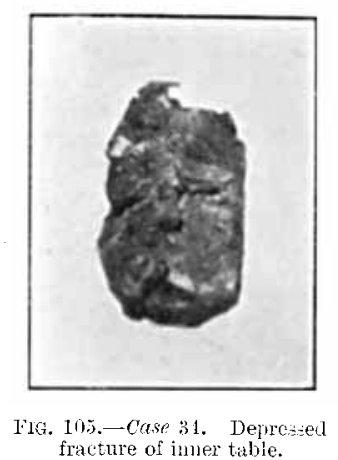

fracture of imer table.

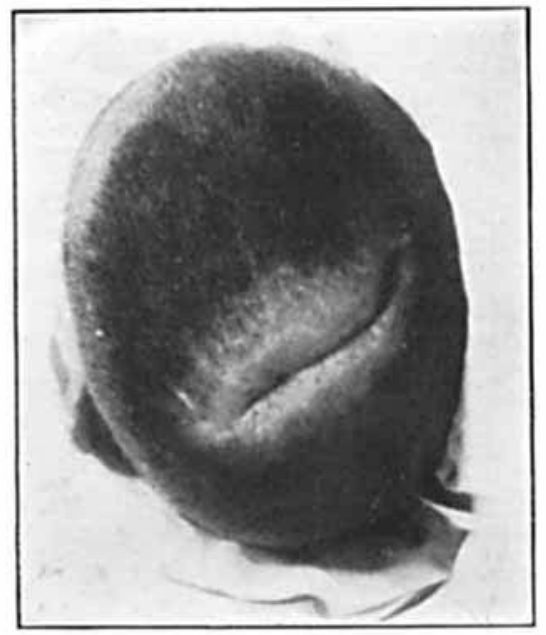

J'Ju. losi.--Case 31. Wound three weeks after operation.

fully controlled by a graft from the epicranial aponeurosis. The wound was then sutured, without drainage. It healed uneventfully (Fig. 106).

The following case illustrates an injury of the lateral sinus. The wound was small, and the hamorrhage was easily controlled by a muscle graft.

Case 35.-Pte. E. W. Admitted six hours after injury.

On Admission.--There was a large laccrated wound in the occipital region extending across the mid-line.

Operation.-The wound was excised and a depressed fracture of the occipital bone removed. One fragment had penetrated the left lateral sinus $1 \mathrm{~cm}$. to the left of the torcula. It was removed, and a graft from the complexus muscle applied. There was also a superficial laceration of the cerebellum. This was irrigated and the dural wound sutured. The wound was sutured, with a glove-drain in silu. The drain was removed on the second day. The wound healed by first intention.

In a subsequent report two months later the patient stated that he was quite well.

Of the two remaining cases of injury to the longitudinal sinus, the wound in the first. was small and was situated in the frontal region; whilst in the second case it was $2 \mathrm{~cm}$. ventral to the torcula. Neither in this latter case nor in Case 34 was 'a sinus syndrome' observed.

This syndrome was described by Holmes and Sargent.11 It is characterized by a paresis of unusual distribution, affecting the lower, and frequently the upper, limbs in various combinations. This paresis is more marked in the proximal segments in the upper limbs and the distal segments in the lower limbs; the paresis is accompanied by a striking degree of rigidity. Sensory disturbances of a cortical type are usually present. There is an absence of shock to the lower centres, which reflexly maintain tone. The peculiar distribution of the paresis is explained by the arrangement of the cortical motor centres and the cortical veins. The symptoms are attributed by the authors to the venous lesions present. As this syndrome has been usually observed in lesions over the motor cortex, and has not been observed in sinus lesions posterior to this area, it is generally held that the factor of direct concussion to the cortex must play an important part in the etiology. 


\section{THE BRITISH JOURNAL OF SURGERY}

\section{CONCLUSIONS.}

1. Operation should be performed at the earliest possible moment after the infliction of the wound.

2. Local anæsthesia should be employed.

3. The wound should be completely excised, the fracture removed en bloc, and the brain wound cleaned gently and thoroughly by the catheter method.

4. In the infected wounds the B.I.P.P. pack method is of great service.

5. The prognosis depends largely upon the extent of the cerebral injury.

6. 'The real gravity of cerebral wounds can only be judged by statistics extending over long periods. The results will be influenced by two factors : $(a)$ The extent of the cerebral lesion; and $(b)$ The completeness of the operation.

7. A careful, gentle, and thorough cleansing of the cerebral wound will reward the surgeon a thousandfold for the time spent in its accomplishment.

\section{REFERENCES.}

1 Coshisg, Brit. Jour. Surg., 1918, v, 558.

2 Cushria, Brit. Med. Jour., 1918, Feb. 23

3 Anatomy of Melancholy, iii.

4 MarTel, Bull. et Mém. Soc. de Chir. de Paris, 1918, xliv, 1364.

5 Gray, Brit. Med. Jour., 1916, i, 261.

- Wrudeys, Bull. et Mém. Sor. de Chir. de Paris, 1918, xliv, 1344.

7 Fergeson, Brit. Jour. Surg., 1919, vi, 409.

8 Monprofit and Courty, Arch. de Méd. et de Pharm. Mil., Paris : 1917, lxvi, 790

- Majere, quoted by Willems (v, supra).

10 Velter, Penetrating Gunshot Wounds of the Head. Paris: Maloino et Fils.

11 Honves and SARGest, Brit. Med. Jour. 1915, ii, 493. 